\title{
Supplementary Material Screening for pharmaceutical cocrystal hydrates via neat and liquid-assisted grinding
}

\author{
Shyam Karki, ${ }^{a}$ Tomislav Friščić, ${ }^{a}$ William Jones ${ }^{\mathrm{a} *}$ and W. D. Samuel Motherwell ${ }^{\mathrm{b}}$
}

Figure S1. X-ray powder diffraction pattern of theophylline, following neat grinding. 3

Figure S2. X-ray powder diffraction pattern of caffeine, following neat grinding. 3

Figure S3. $\quad$ X-ray powder diffraction pattern of citric acid, following neat grinding. 4

Figure S4. X-ray powder diffraction pattern of 1, prepared by neat grinding of a 1:1 mixture of theophylline 4 and citric acid.

Figure S5. X-ray powder diffraction pattern of 2, prepared by neat grinding of a 1:1 mixture of theophylline 5 monohydrate and citric acid.

Figure S6. X-ray powder diffraction pattern of 2, prepared by neat grinding of a 1:1 mixture of theophylline 5 and citric acid monohydrate.

Figure S7. X-ray powder diffraction pattern of 2, prepared by neat grinding of a 1:1 mixture of theophylline monohydrate and citric acid monohydrate.

Figure S8. X-ray powder diffraction pattern of 2, prepared by liquid-assisted grinding of a 1:1 mixture of theophylline and citric acid in the presence of water.

Figure S9. X-ray powder diffraction pattern of 2, prepared by liquid-assisted grinding of a 1:1 mixture of theophylline hydrate and citric acid in the presence of water.

Figure S10. X-ray powder diffraction pattern of a 1:1 mixture of caffeine and citric acid, after neat grinding.

Figure S11. X-ray powder diffraction pattern of 3, prepared by neat grinding of a 1:1 mixture of caffeine hydrate and citric acid.

Figure S12. X-ray powder diffraction pattern of a 1:1 mixture of caffeine and citric acid monohydrate after neat grinding.

Figure S13. X-ray powder diffraction pattern of 3, prepared by neat grinding of a 1:1 mixture of caffeine hydrate and citric acid monohydrate.

Figure S14. X-ray powder diffraction pattern of 3, prepared by liquid-assisted grinding of a 1:1 mixture of caffeine and citric acid in the presence of water.

Figure S15. X-ray powder diffraction pattern of 3, prepared by liquid-assisted grinding of a 1:1 mixture of caffeine hydrate and citric acid in the presence of water.

Figure S16. X-ray powder diffraction pattern of 1 after 7 days standing at $0 \%$ relative humidity. 
Figure S17. X-ray powder diffraction pattern of 1 after 7 days standing at $43 \%$ relative humidity.

Figure S18. X-ray powder diffraction pattern of 1 after 7 days standing at $75 \%$ relative humidity.

Figure S19. X-ray powder diffraction pattern of 1 after 7 days standing at $98 \%$ relative humidity.

Figure S20. X-ray powder diffraction pattern of 2 after 7 days standing at $0 \%$ relative humidity.

Figure S21. X-ray powder diffraction pattern of 2 after 7 days standing at $43 \%$ relative humidity.

Figure S22. X-ray powder diffraction pattern of 2 after 7 days standing at $75 \%$ relative humidity.

Figure S23. X-ray powder diffraction pattern of 2 after 7 days standing at $98 \%$ relative humidity.

Figure S24. X-ray powder diffraction pattern of 3 after 7 days standing at $0 \%$ relative humidity.

Figure S25. X-ray powder diffraction pattern of 3 after 7 days standing at $43 \%$ relative humidity.

Figure S26. X-ray powder diffraction pattern of 3 after 7 days standing at $75 \%$ relative humidity.

Figure S27. X-ray powder diffraction pattern of 3 after 7 days standing at $98 \%$ relative humidity.

Figure S28. X-ray powder diffraction pattern of caffeine hydrate prepared by grinding anhydrous caffeine with water.

Figure S29. X-ray powder diffraction pattern of theophylline hydrate prepared by grinding anhydrous theophylline with water.

Figure S30. X-ray powder diffraction pattern of citric acid monohydrate prepared by grinding anhydrous citric acid with water.

Figure S31. Simulated X-ray powder diffraction pattern of 2 .

Figure S32. Simulated X-ray powder diffraction pattern of 3. 


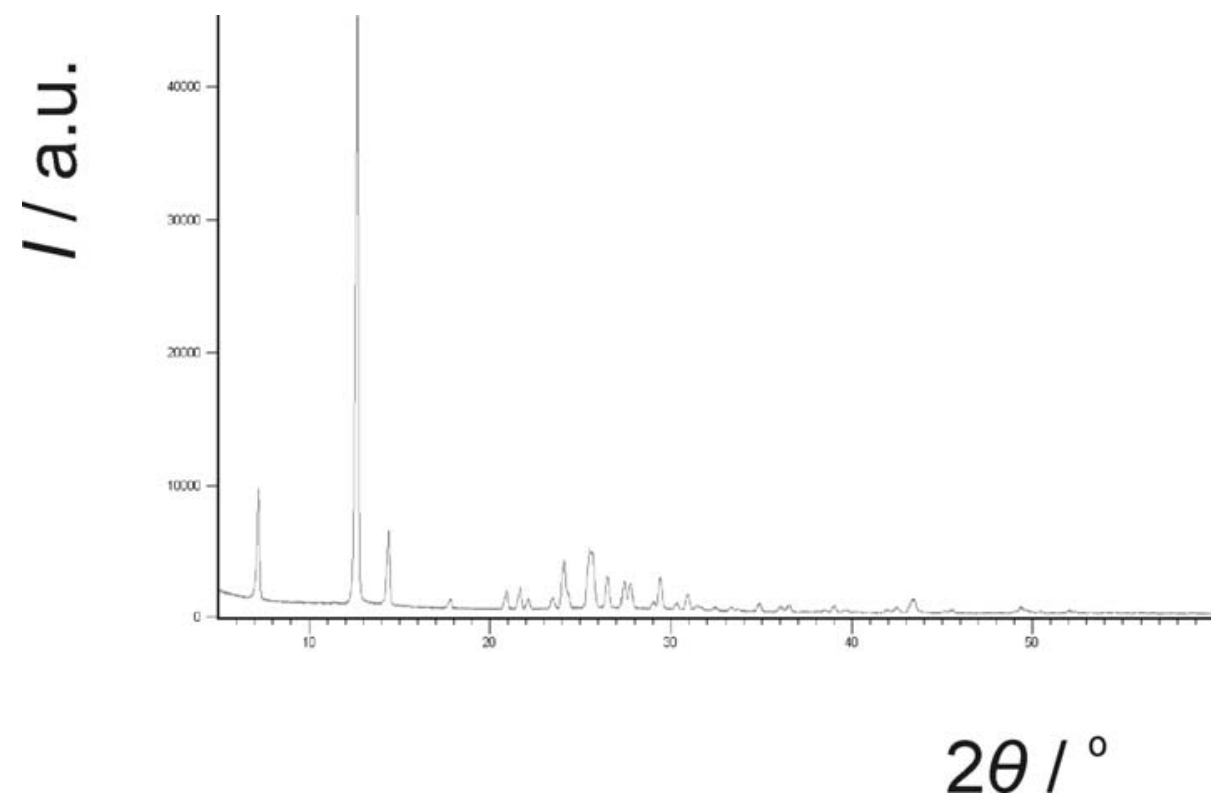

Figure S1. X-ray powder diffraction pattern of theophylline, following neat grinding.

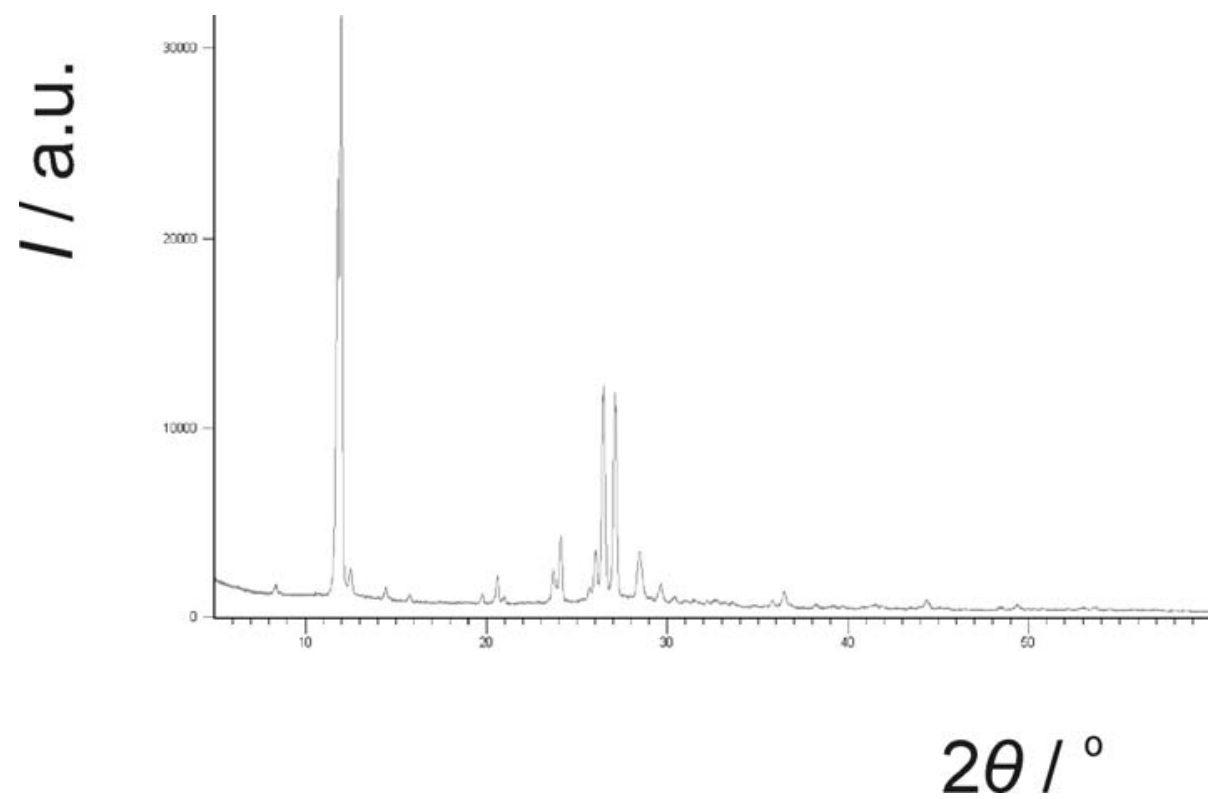

Figure S2. X-ray powder diffraction pattern of caffeine, following neat grinding. 


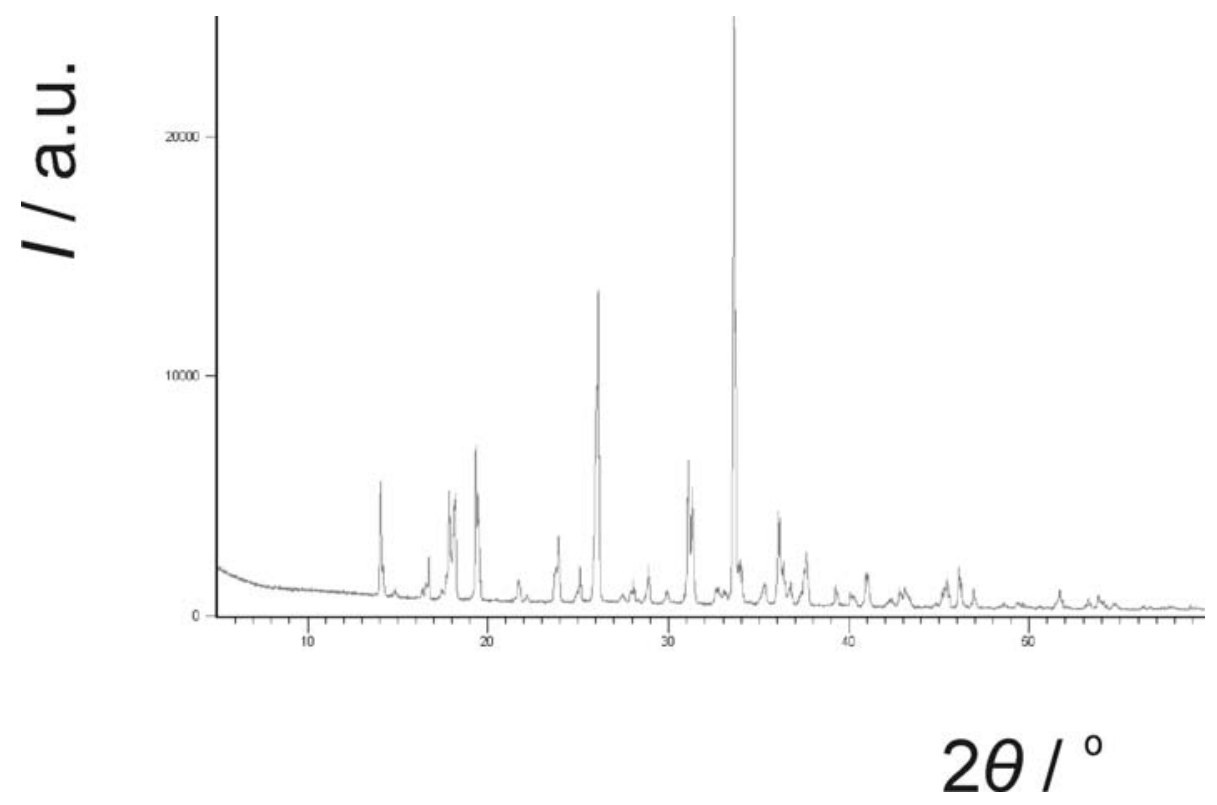

Figure S3. X-ray powder diffraction pattern of citric acid, following neat grinding.

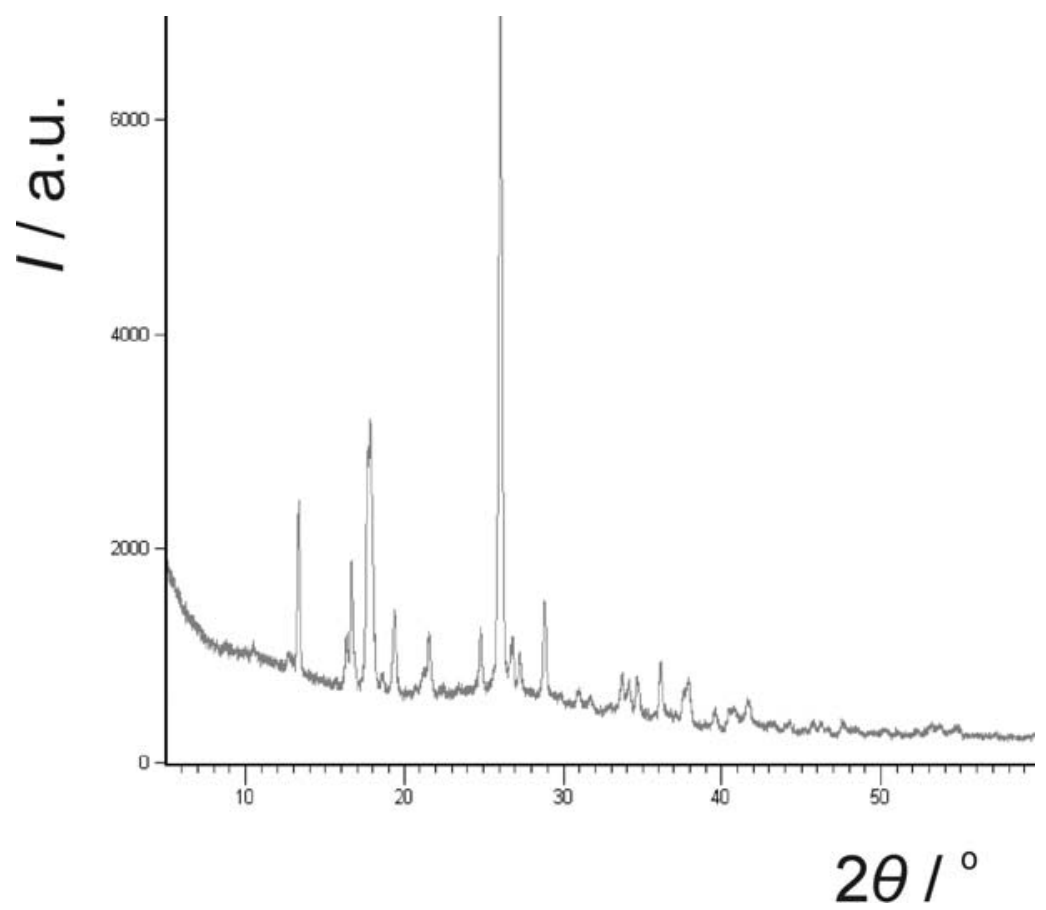

Figure S4. X-ray powder diffraction pattern of $\mathbf{1}$, prepared by neat grinding of a 1:1 mixture of theophylline and citric acid. 


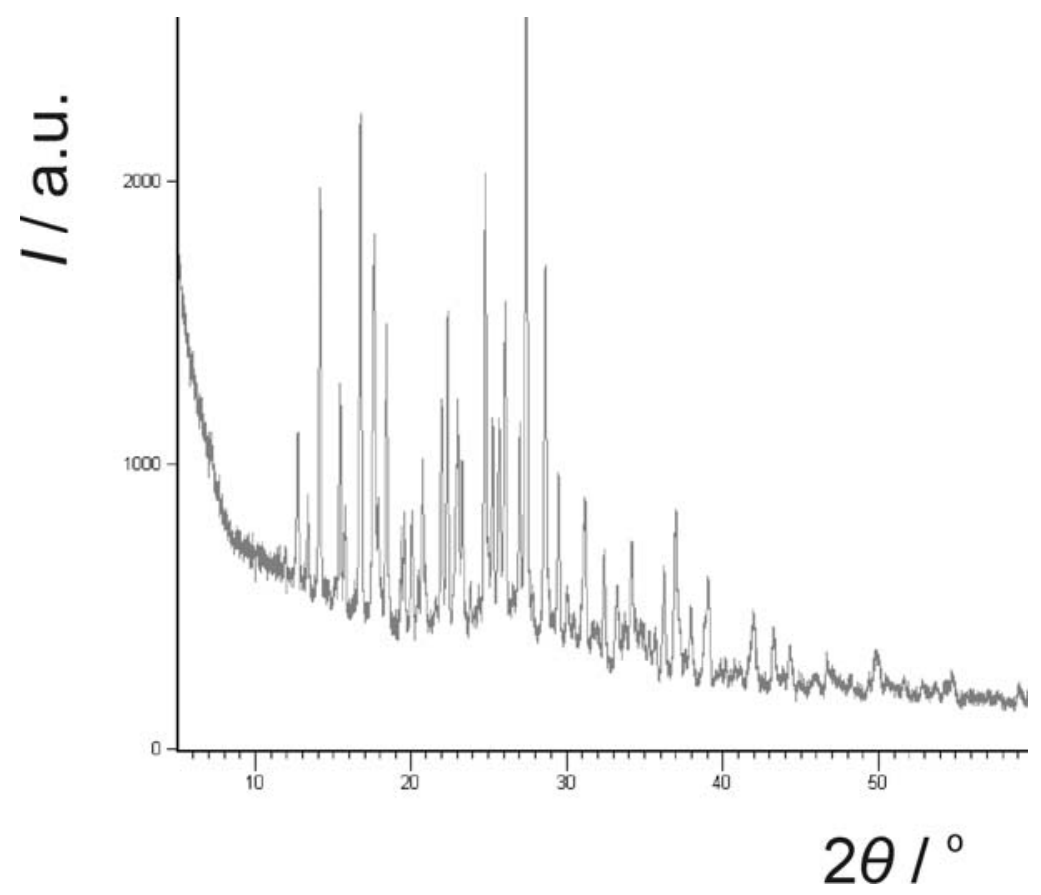

Figure S5. X-ray powder diffraction pattern of 2, prepared by neat grinding of a 1:1 mixture of theophylline monohydrate and citric acid.

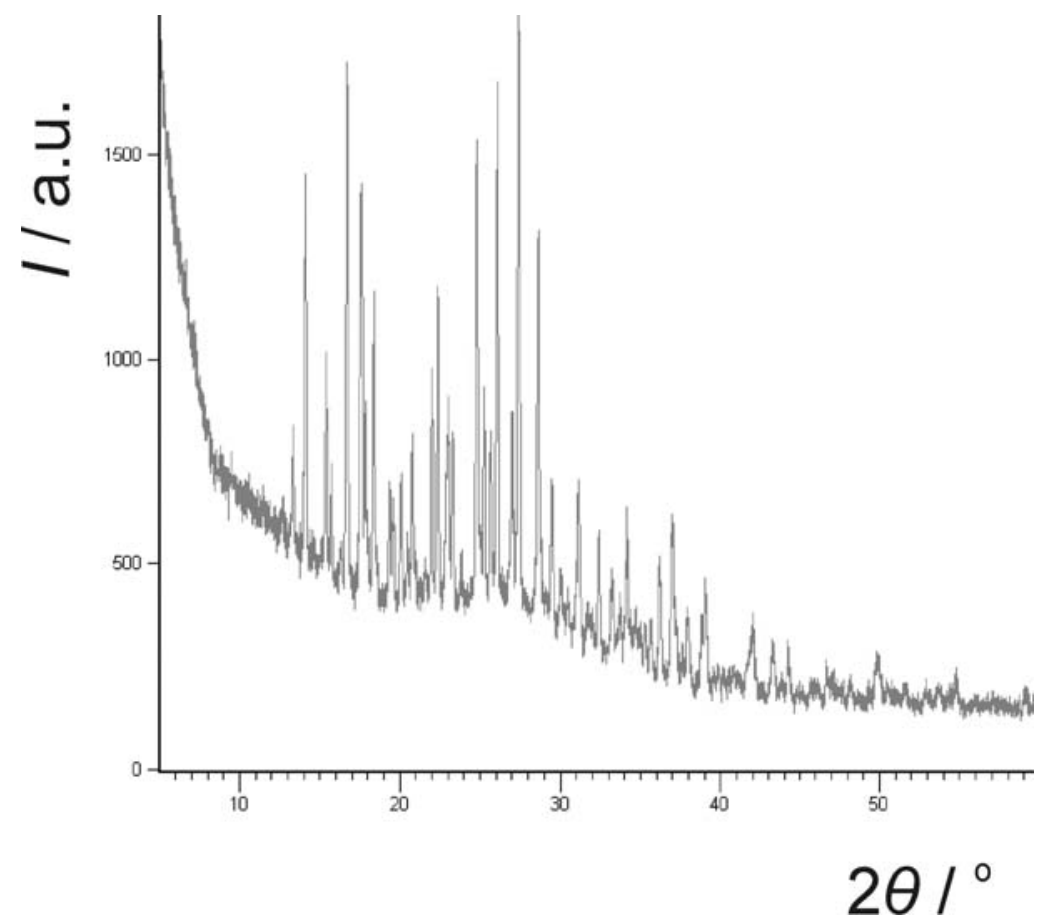

Figure S6. X-ray powder diffraction pattern of 2, prepared by neat grinding of a 1:1 mixture of theophylline and citric acid monohydrate. 


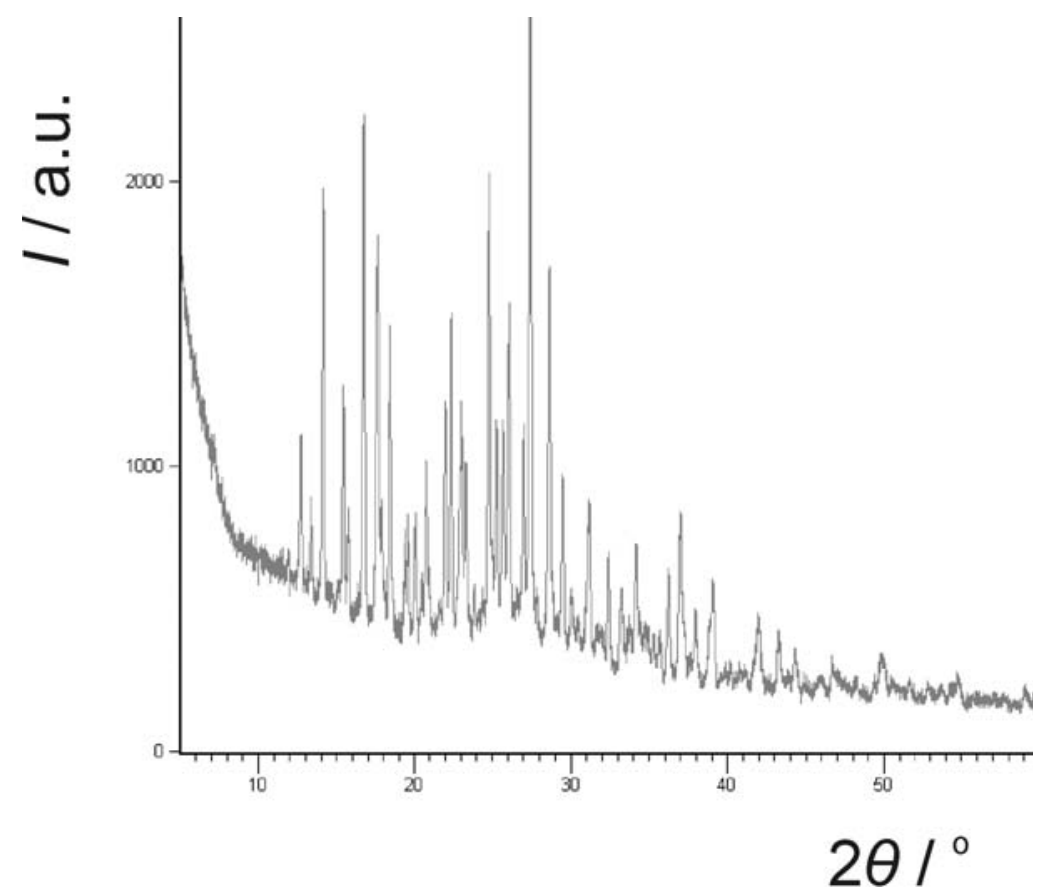

Figure S7. X-ray powder diffraction pattern of 2, prepared by neat grinding of a 1:1 mixture of theophylline monohydrate and citric acid monohydrate.

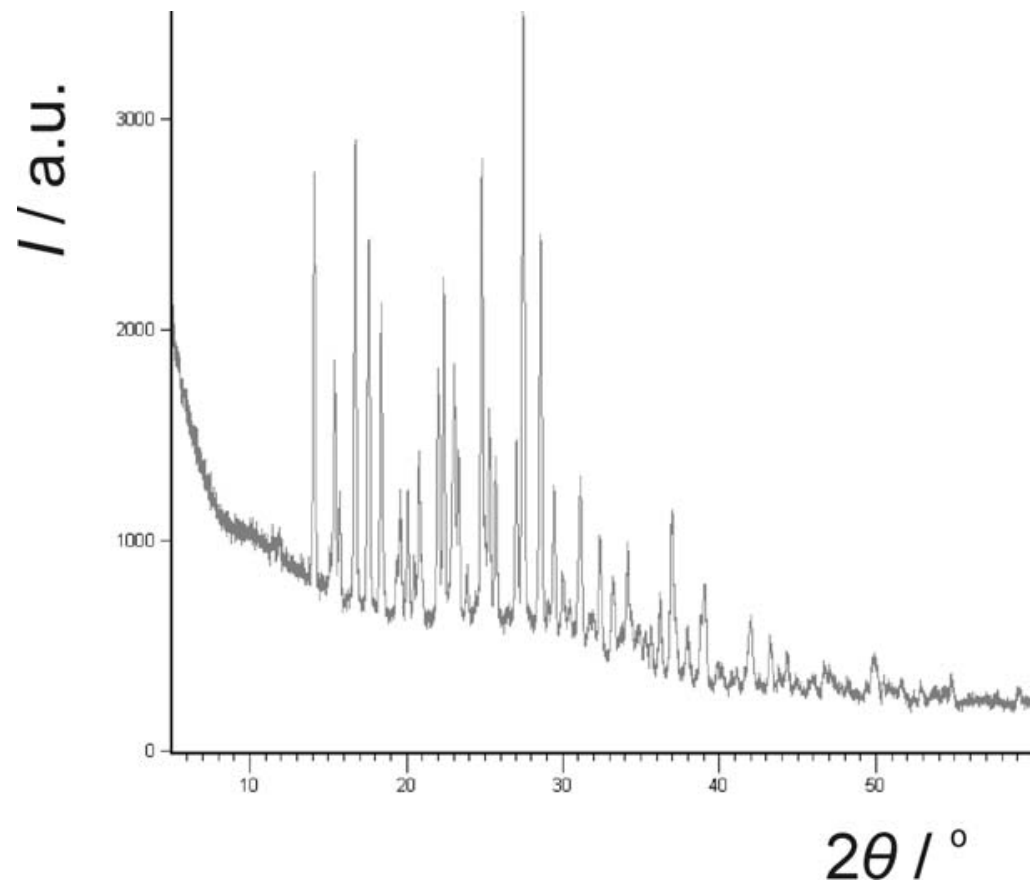

Figure S8. X-ray powder diffraction pattern of 2, prepared by liquid-assisted grinding of a 1:1 mixture of theophylline and citric acid in the presence of water. 


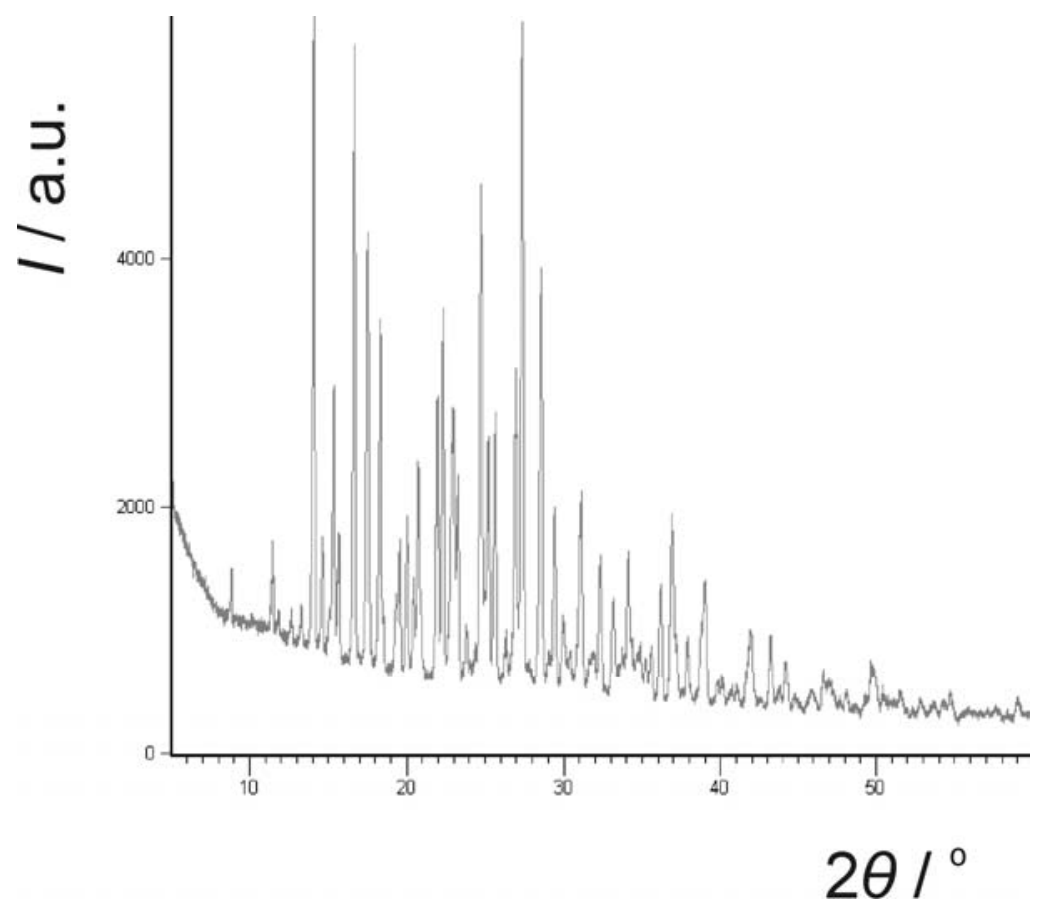

Figure S9. X-ray powder diffraction pattern of 2, prepared by liquid-assisted grinding of a 1:1 mixture of theophylline hydrate and citric acid in the presence of water.

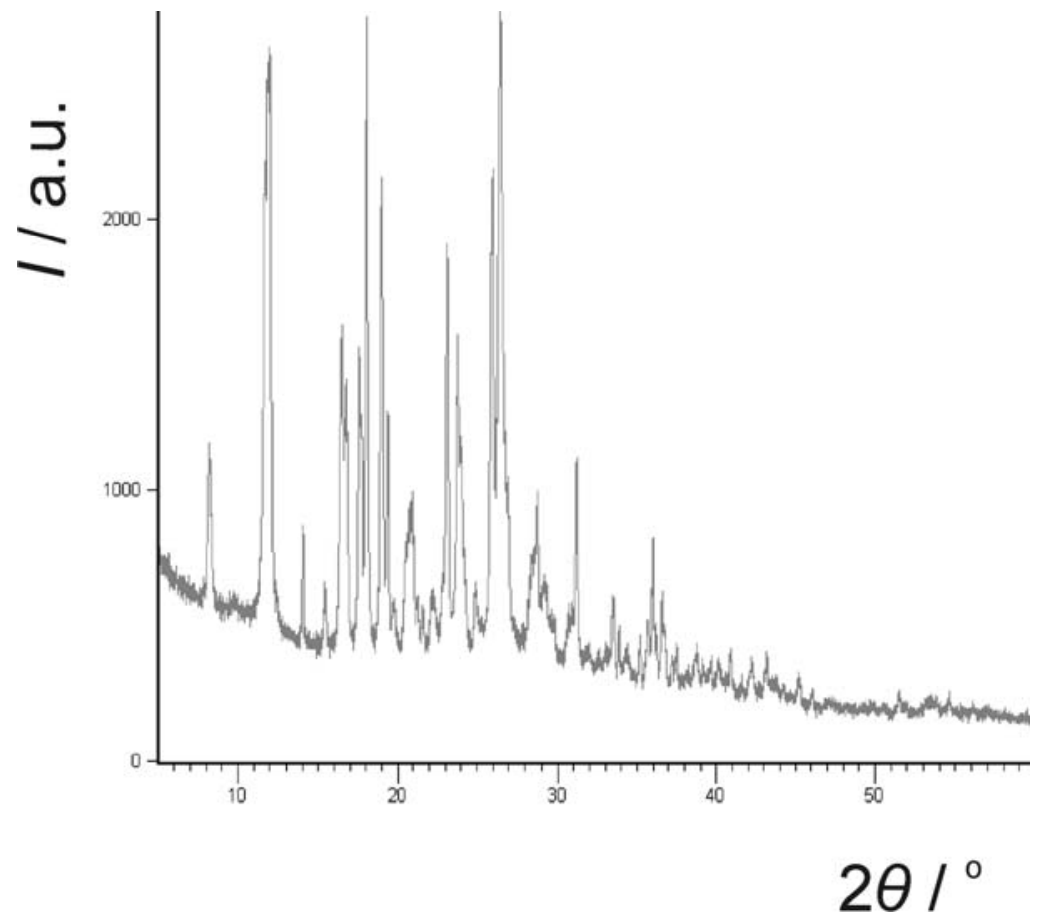

Figure S10. X-ray powder diffraction pattern of a 1:1 mixture of caffeine and citric acid, after neat grinding. 


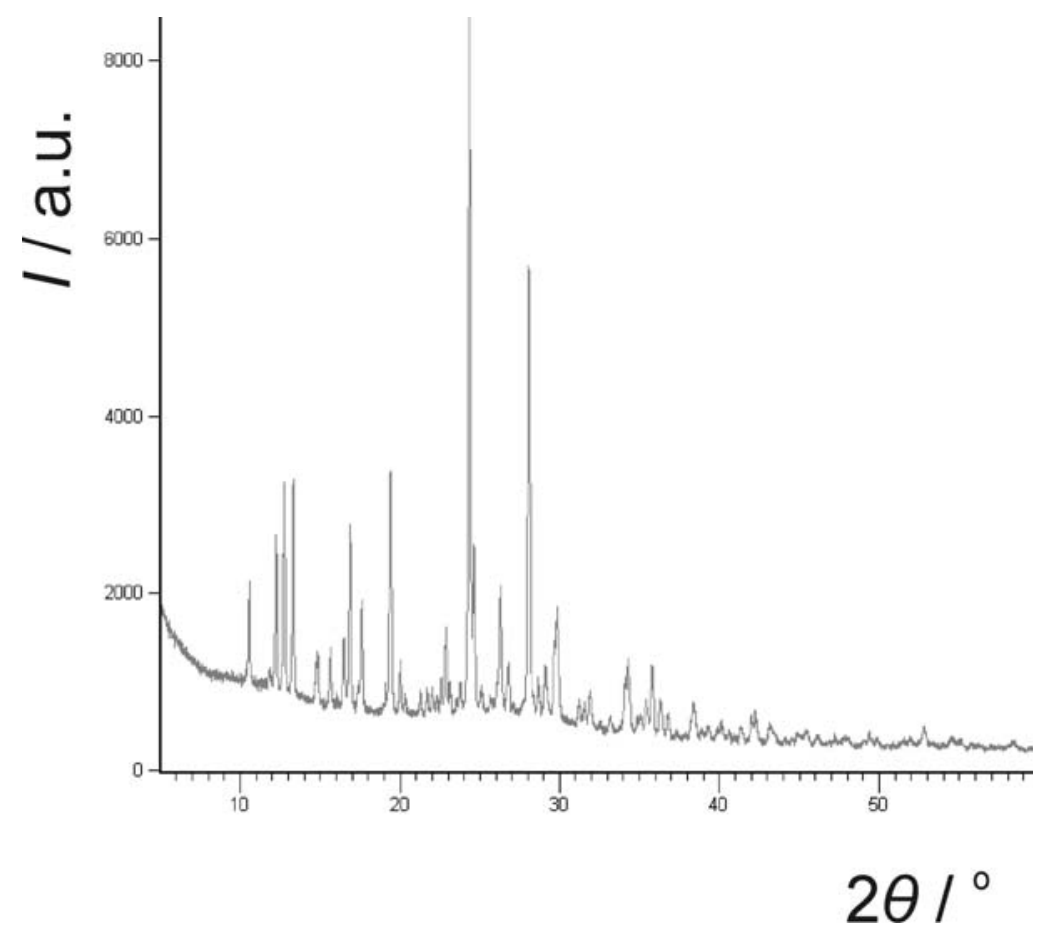

Figure S11. X-ray powder diffraction pattern of 3, prepared by neat grinding of a 1:1 mixture of caffeine hydrate and citric acid.

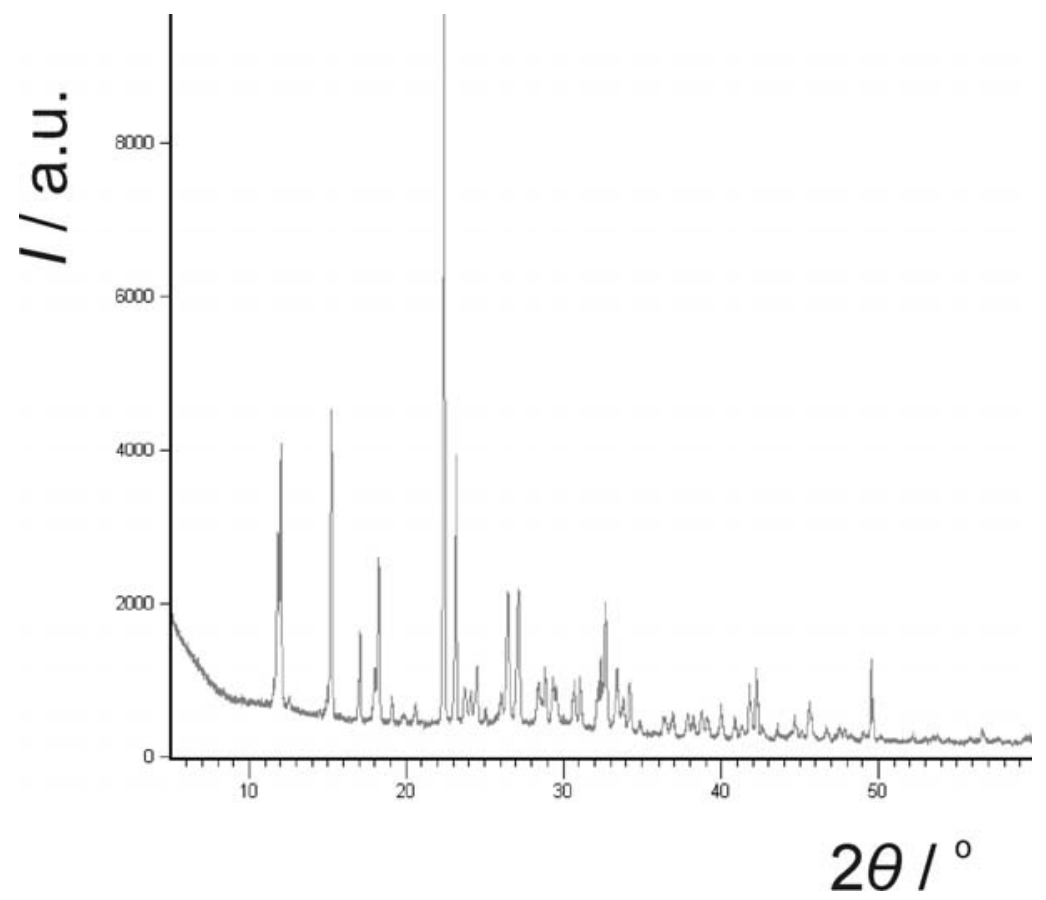

Figure S12. X-ray powder diffraction pattern of a 1:1 mixture of caffeine and citric acid monohydrate after neat grinding. 


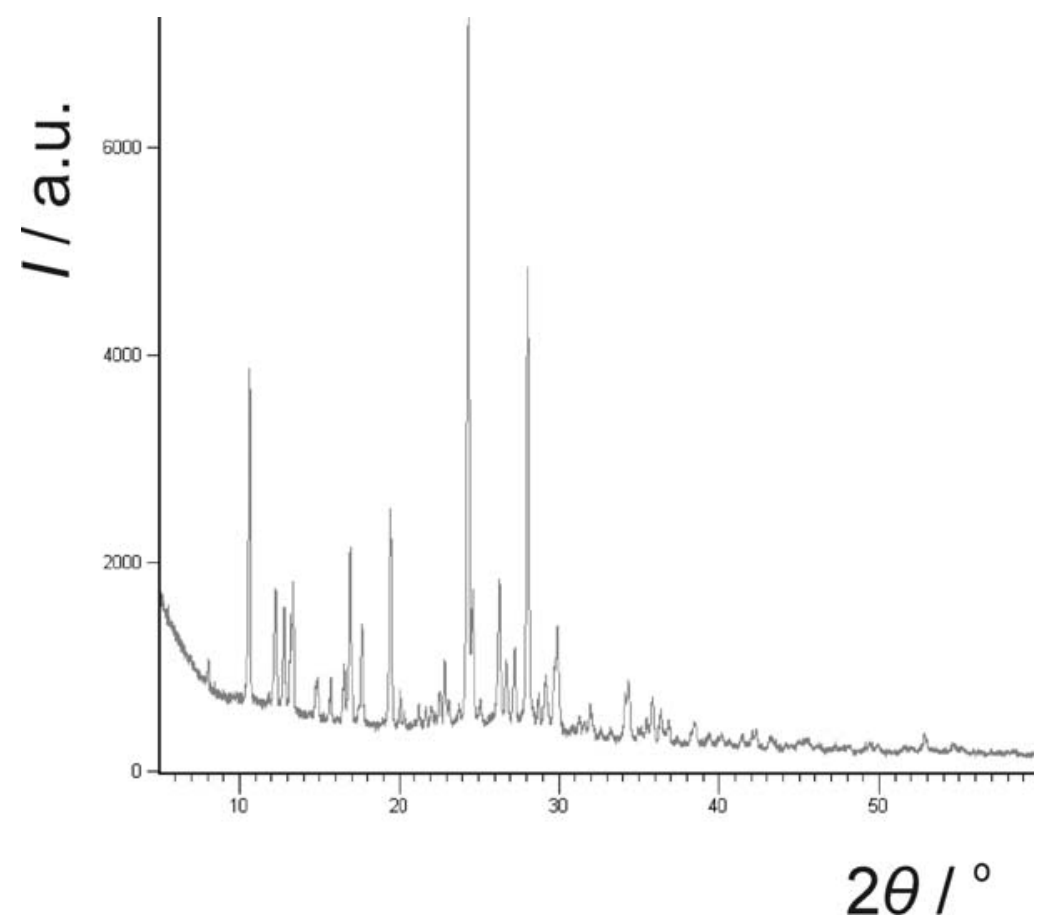

Figure S13. X-ray powder diffraction pattern of 3, prepared by neat grinding of a 1:1 mixture of caffeine hydrate and citric acid monohydrate.

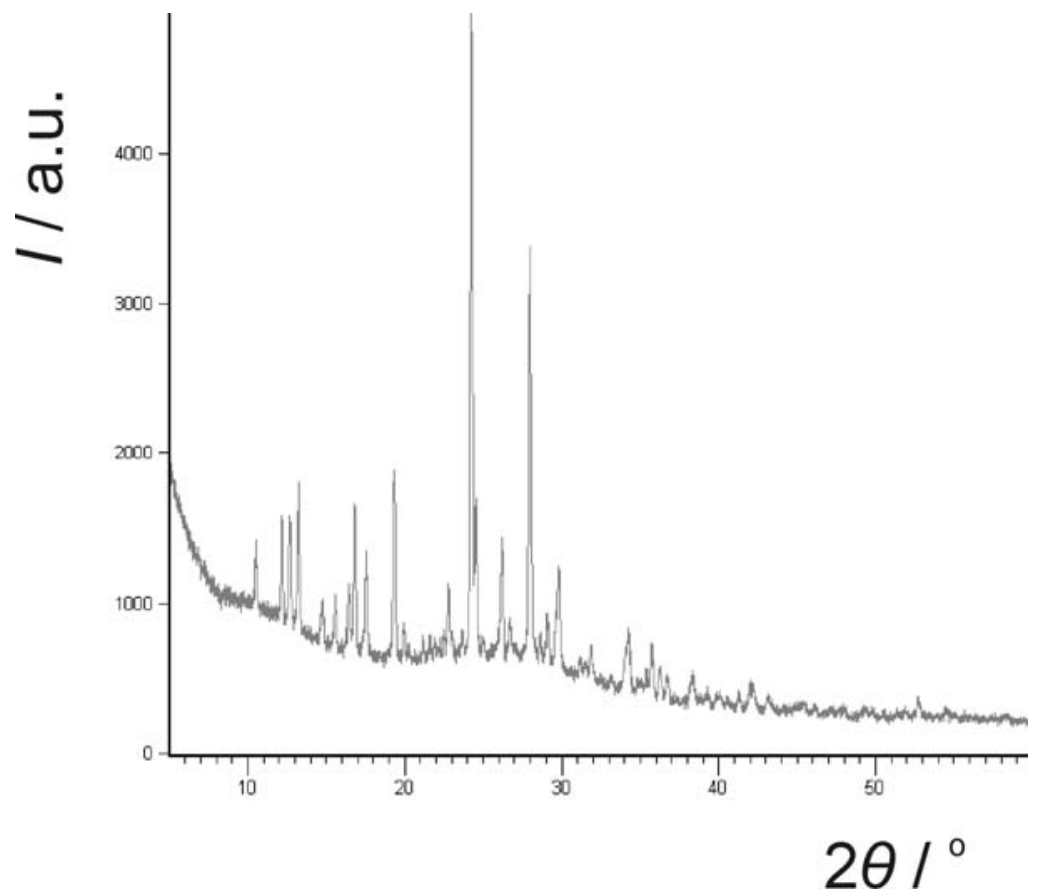

Figure S14. X-ray powder diffraction pattern of 3, prepared by liquid-assisted grinding of a 1:1 mixture of caffeine and citric acid in the presence of water. 


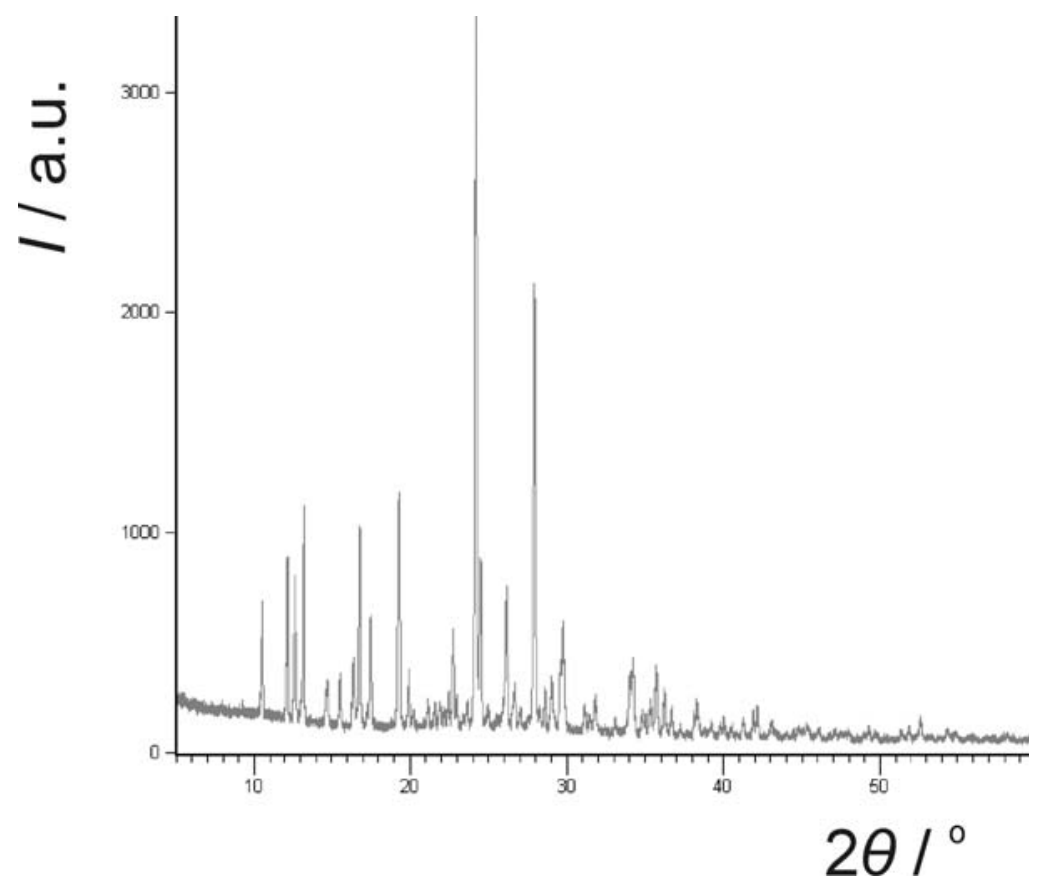

Figure S15. X-ray powder diffraction pattern of 3, prepared by liquid-assisted grinding of a 1:1 mixture of caffeine hydrate and citric acid in the presence of water.

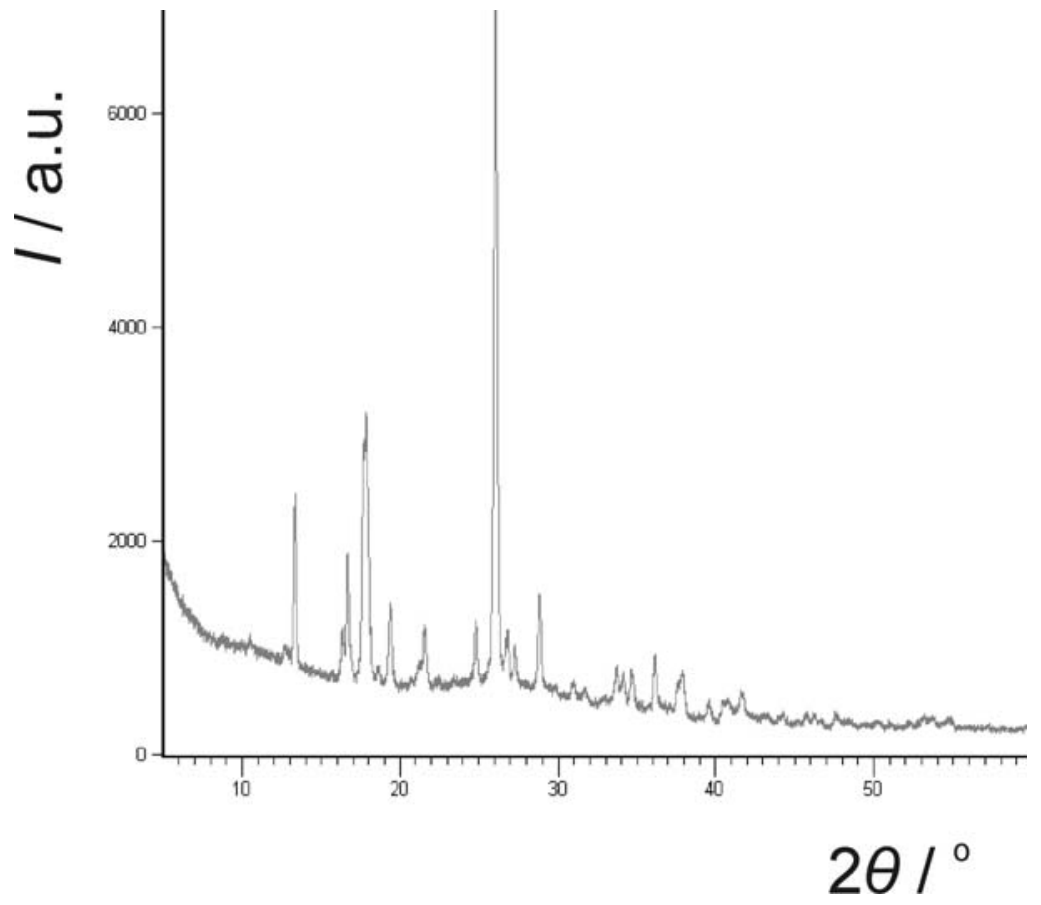

Figure S16. X-ray powder diffraction pattern of 1 after 7 days standing at $0 \%$ relative humidity. 


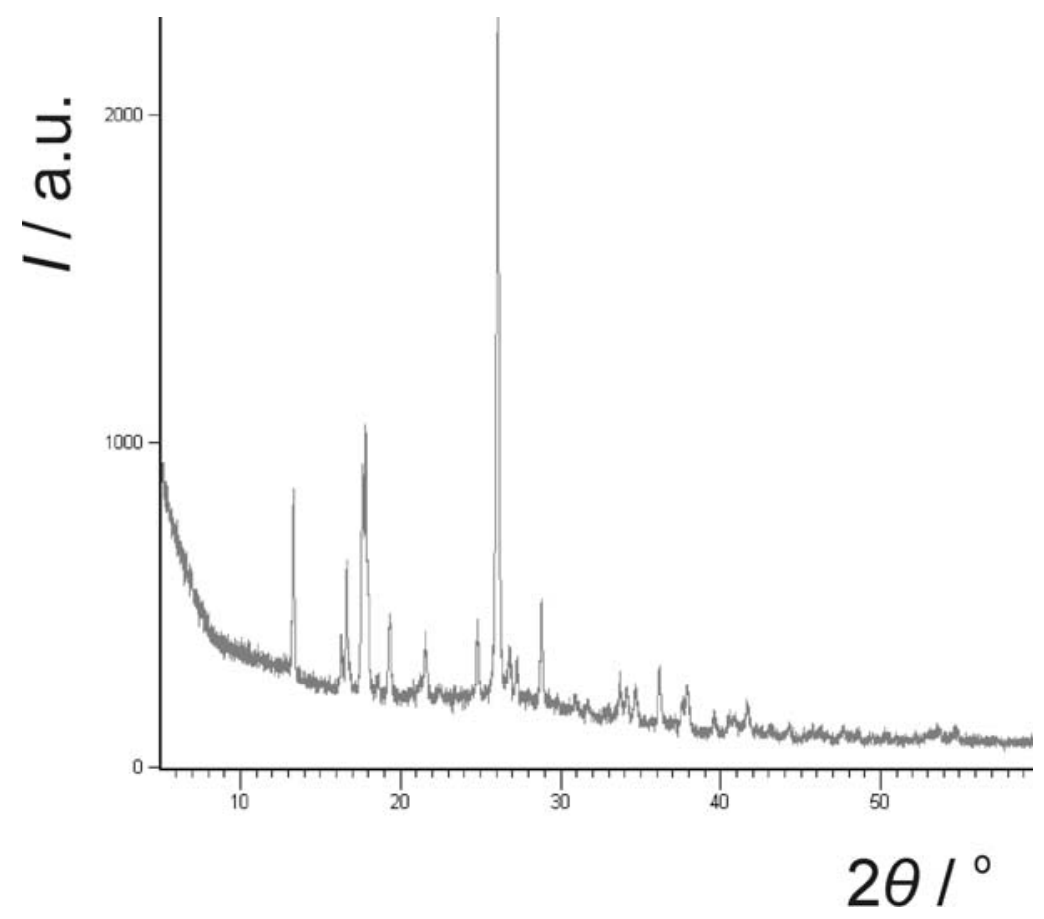

Figure S17. X-ray powder diffraction pattern of 1 after 7 days standing at $43 \%$ relative humidity.

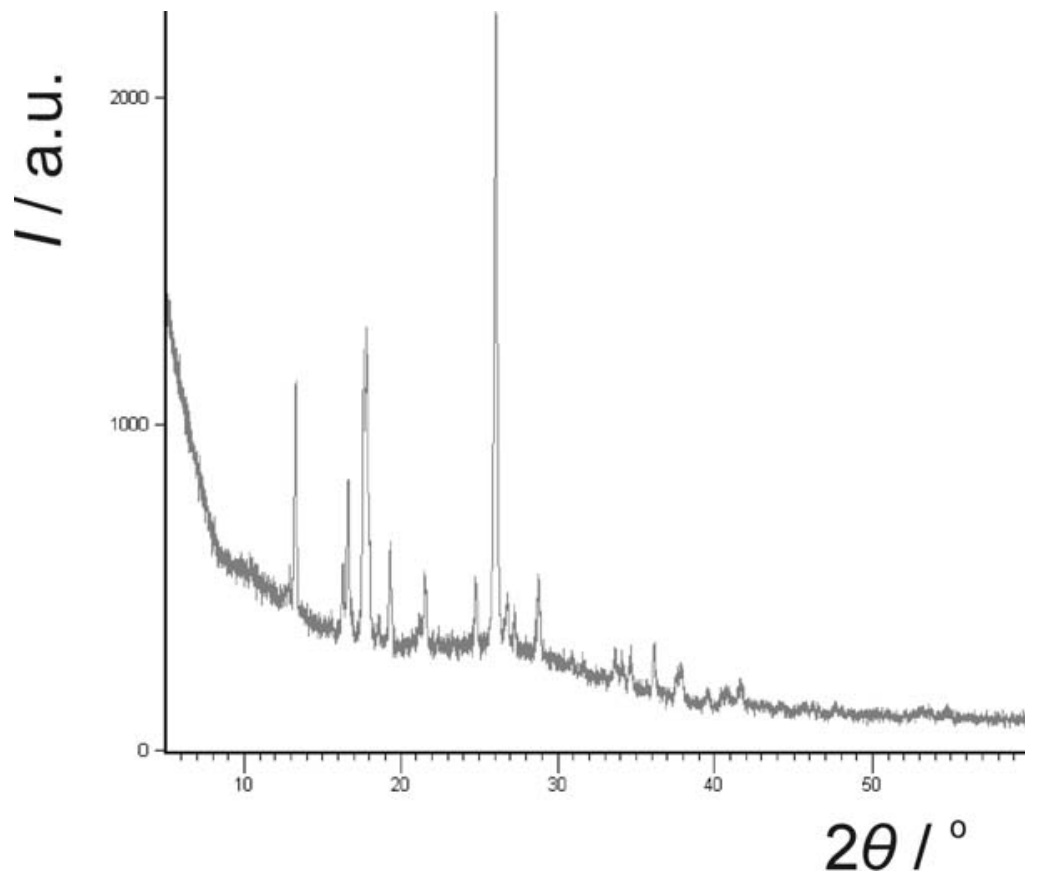

Figure S18. X-ray powder diffraction pattern of 1 after 7 days standing at $75 \%$ relative humidity. 


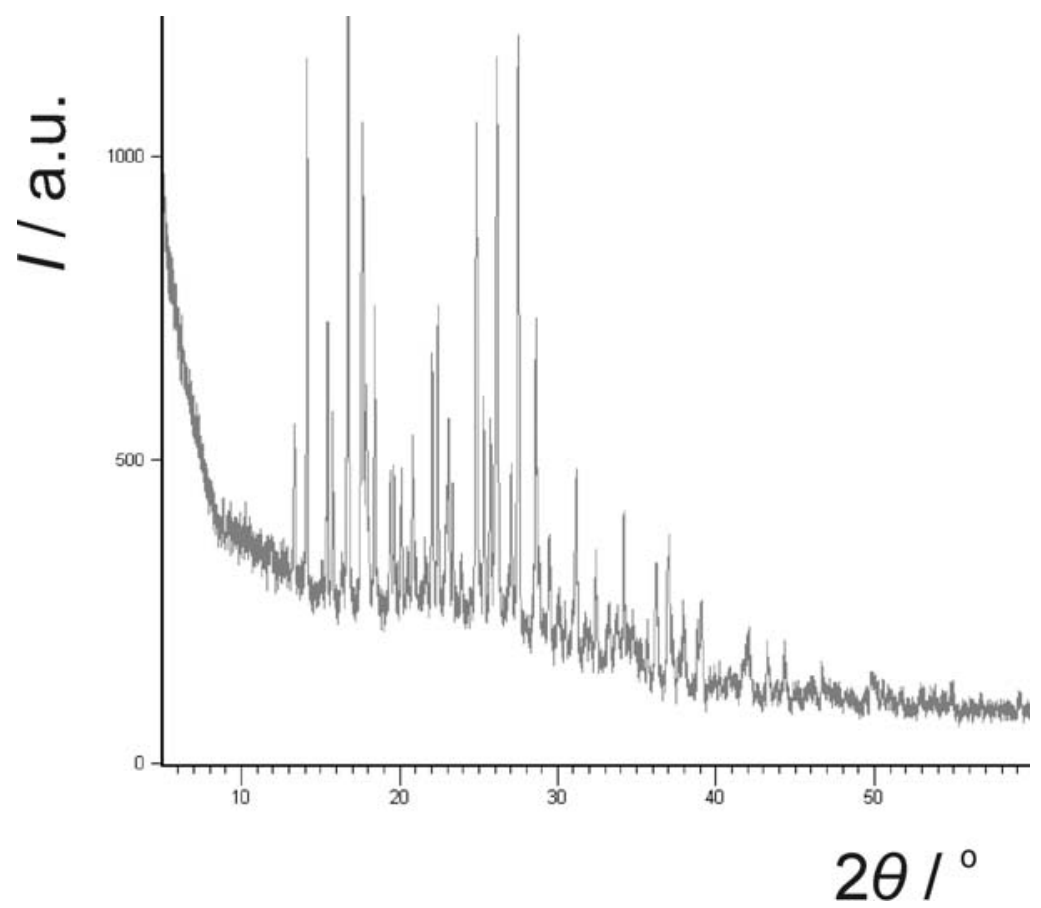

Figure S19. X-ray powder diffraction pattern of 1 after 3 days standing at $98 \%$ relative humidity.

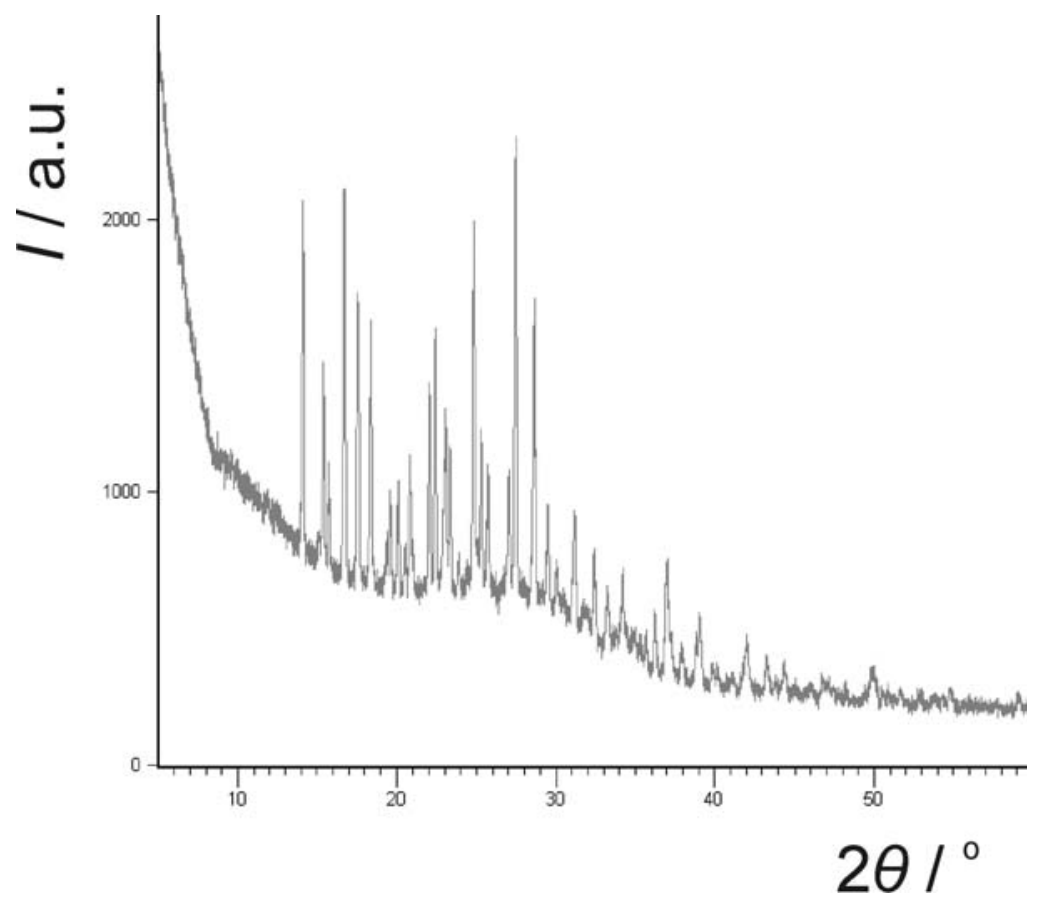

Figure S20. X-ray powder diffraction pattern of 2 after 7 days standing at $0 \%$ relative humidity. 


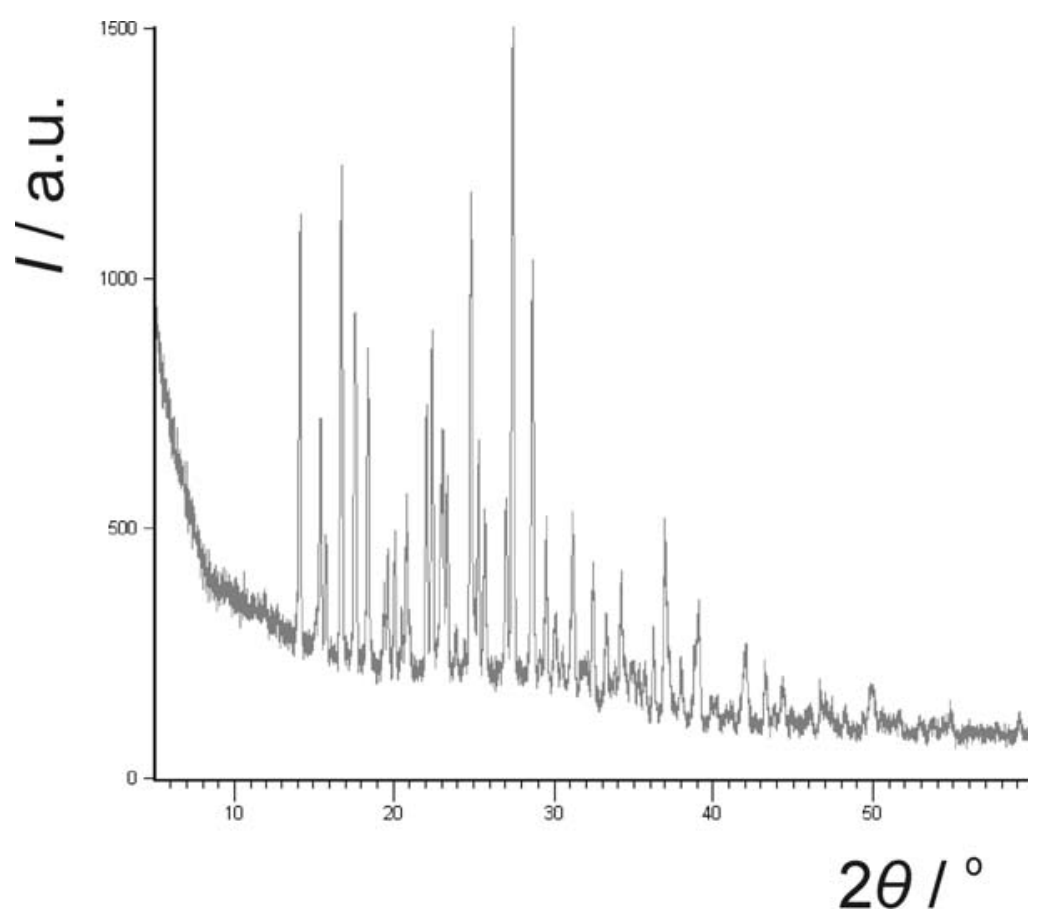

Figure S21. X-ray powder diffraction pattern of 2 after 7 days standing at $43 \%$ relative humidity.

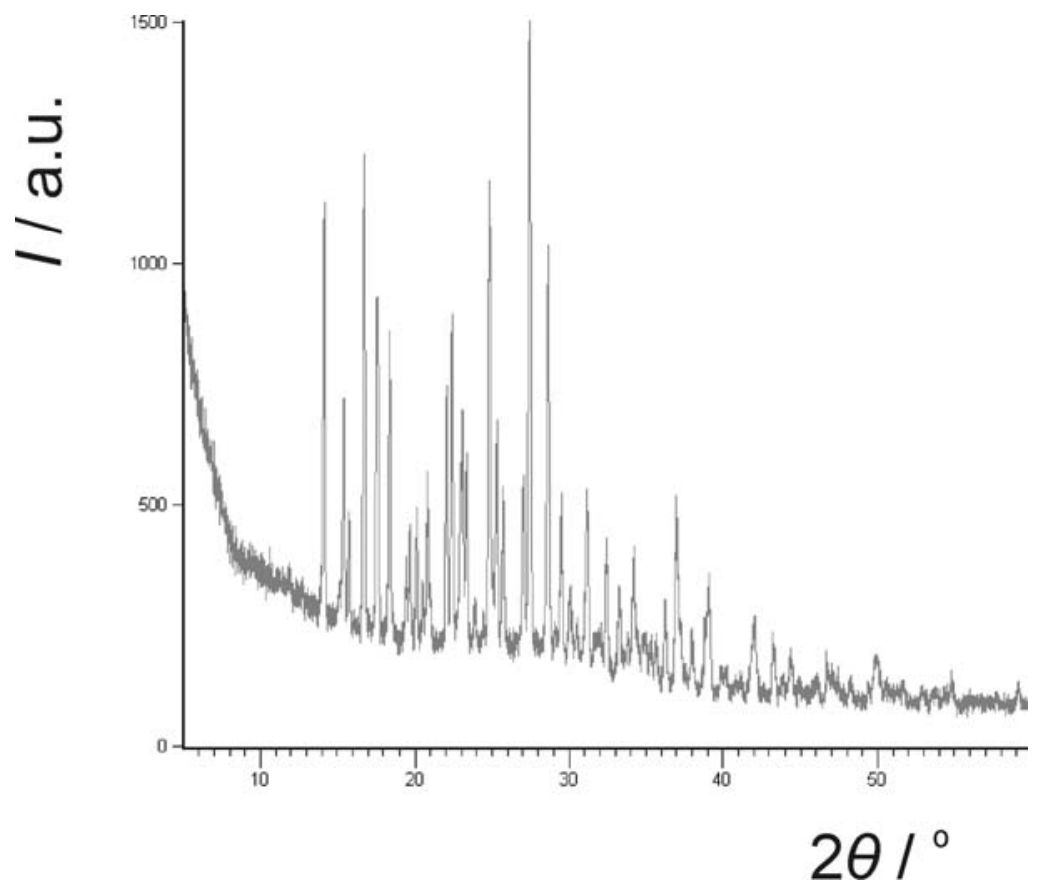

Figure S22. X-ray powder diffraction pattern of 2 after 7 days standing at $75 \%$ relative humidity. 


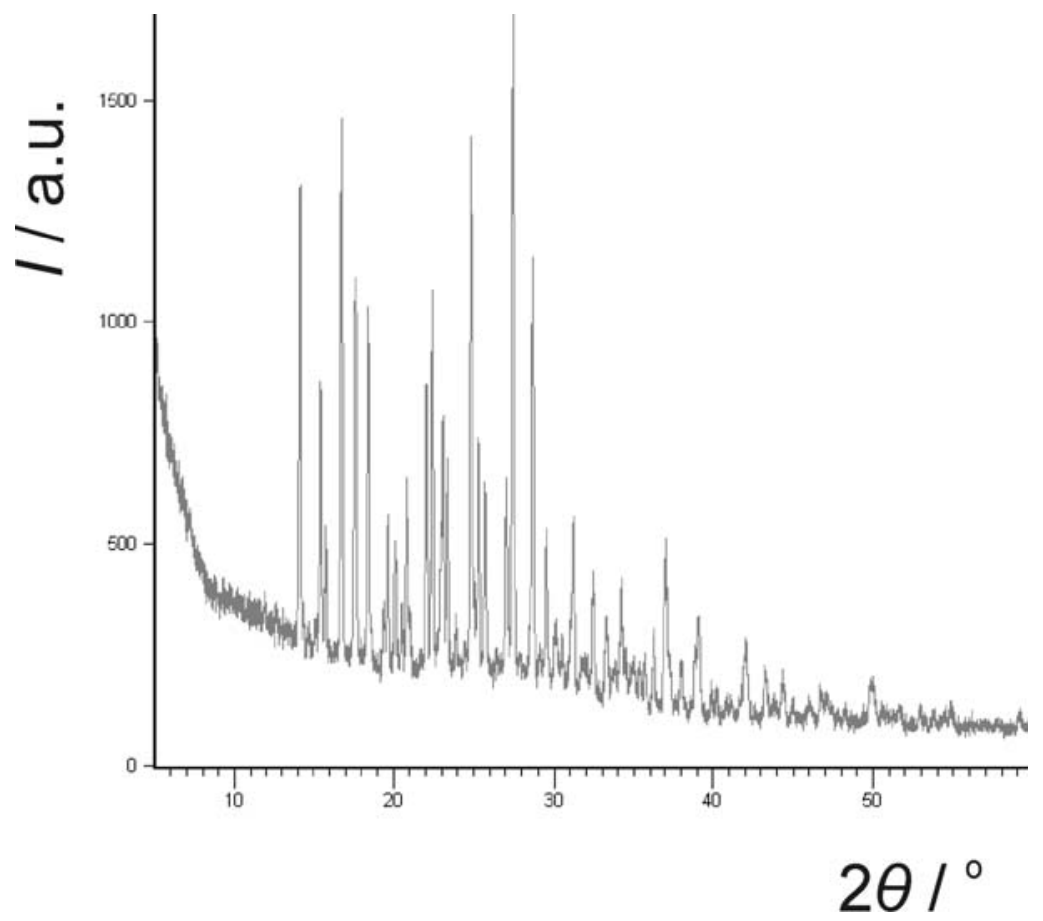

Figure S23. X-ray powder diffraction pattern of 2 after 7 days standing at $98 \%$ relative humidity.

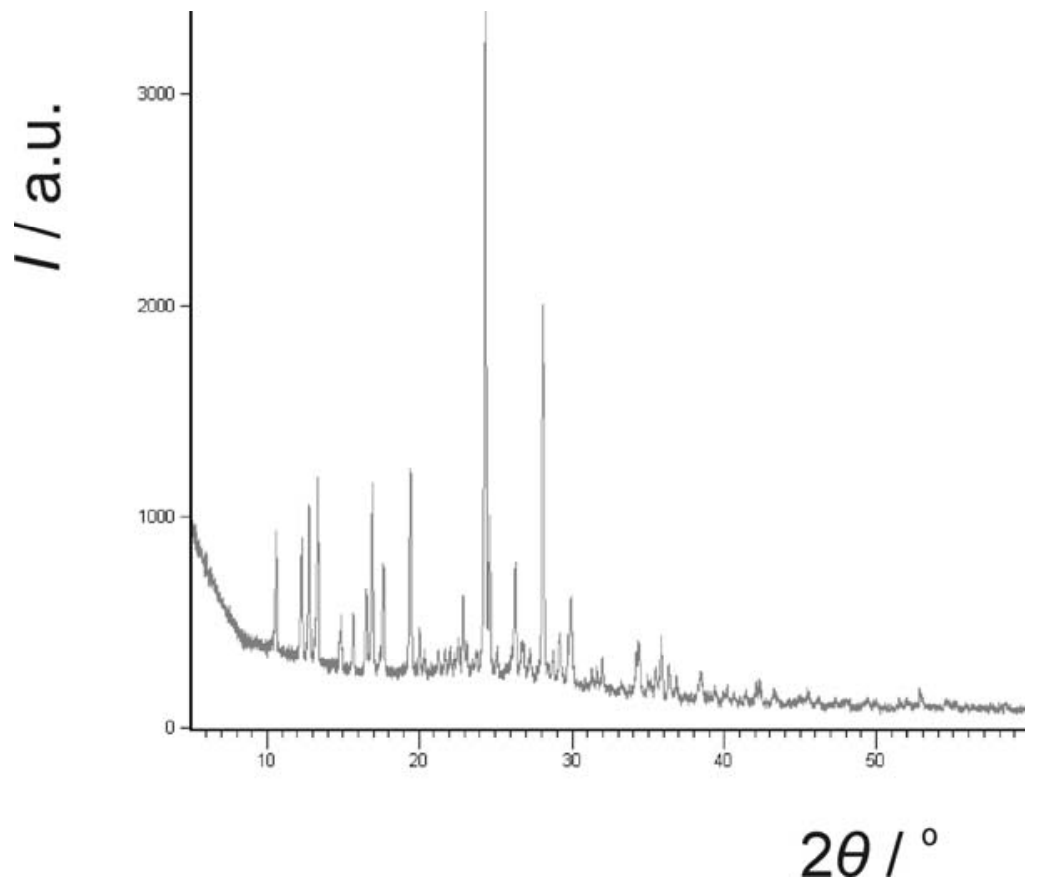

Figure S24. X-ray powder diffraction pattern of 3 after 7 days standing at $0 \%$ relative humidity. 


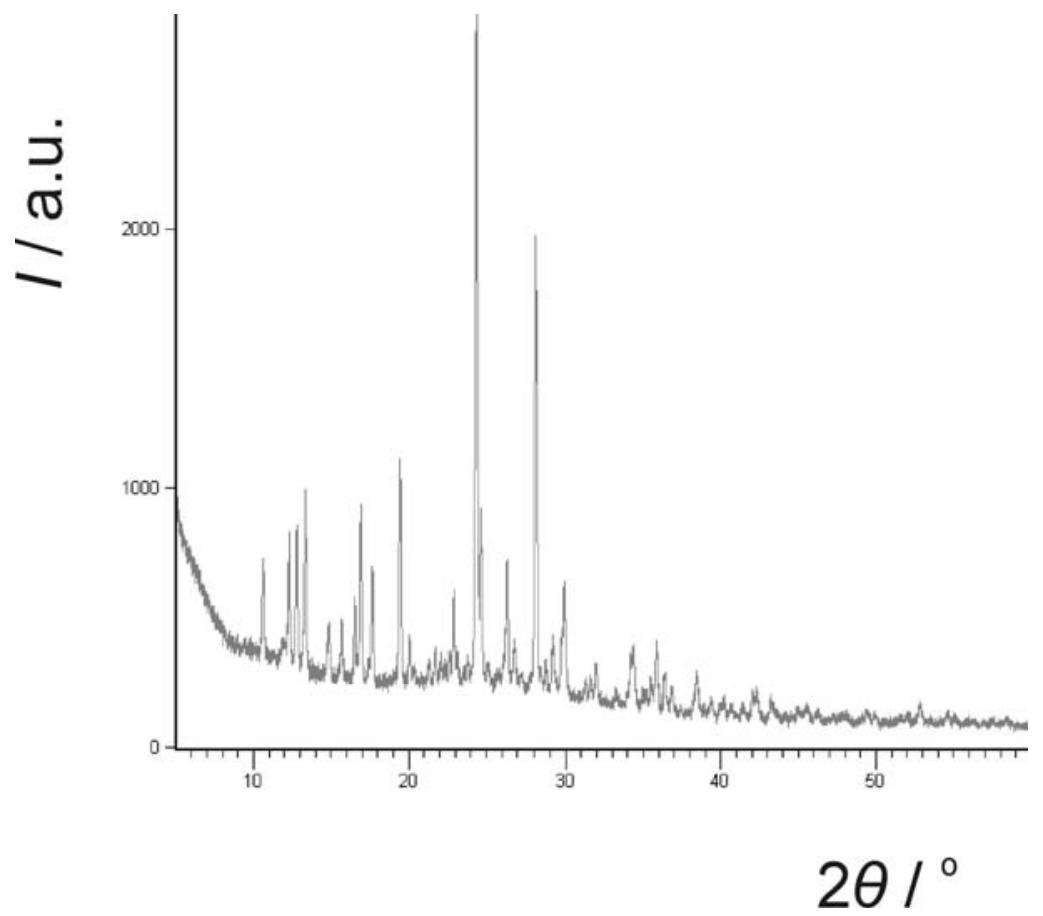

Figure S25. X-ray powder diffraction pattern of 3 after 7 days standing at $43 \%$ relative humidity.

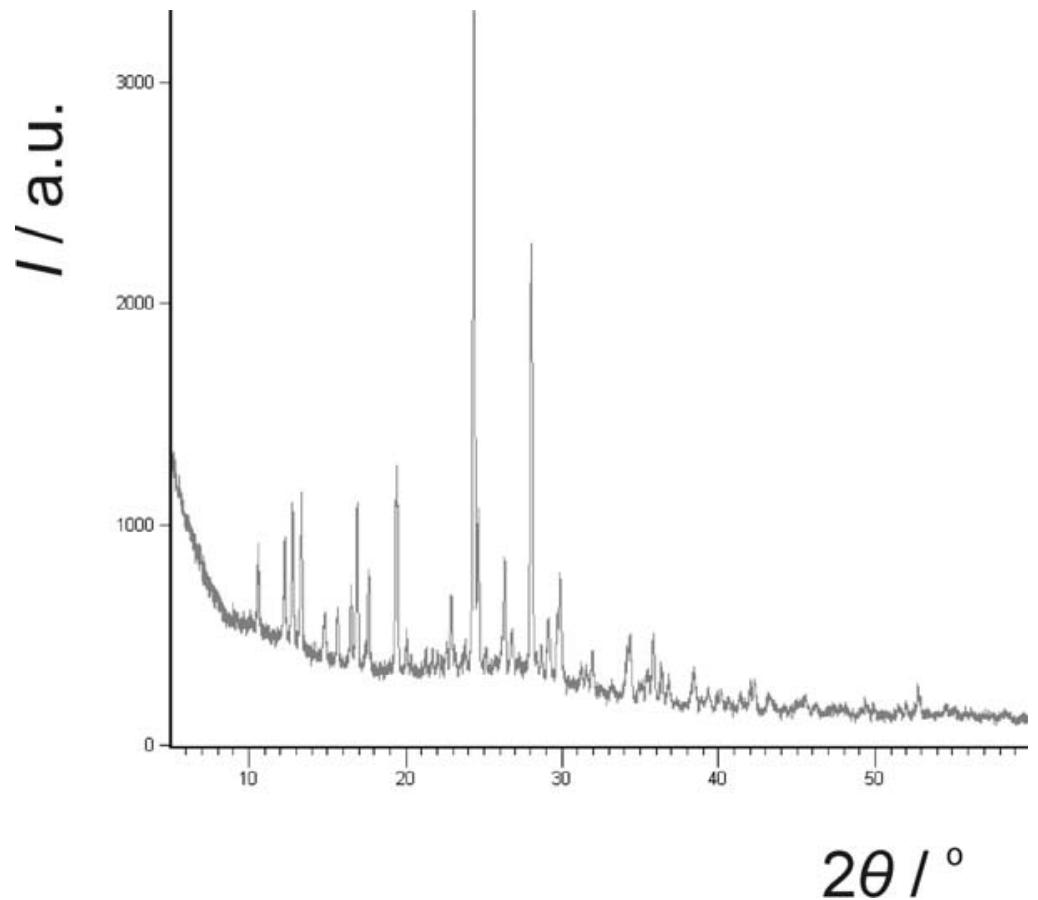

Figure S26. X-ray powder diffraction pattern of 3 after 7 days standing at $75 \%$ relative humidity. 


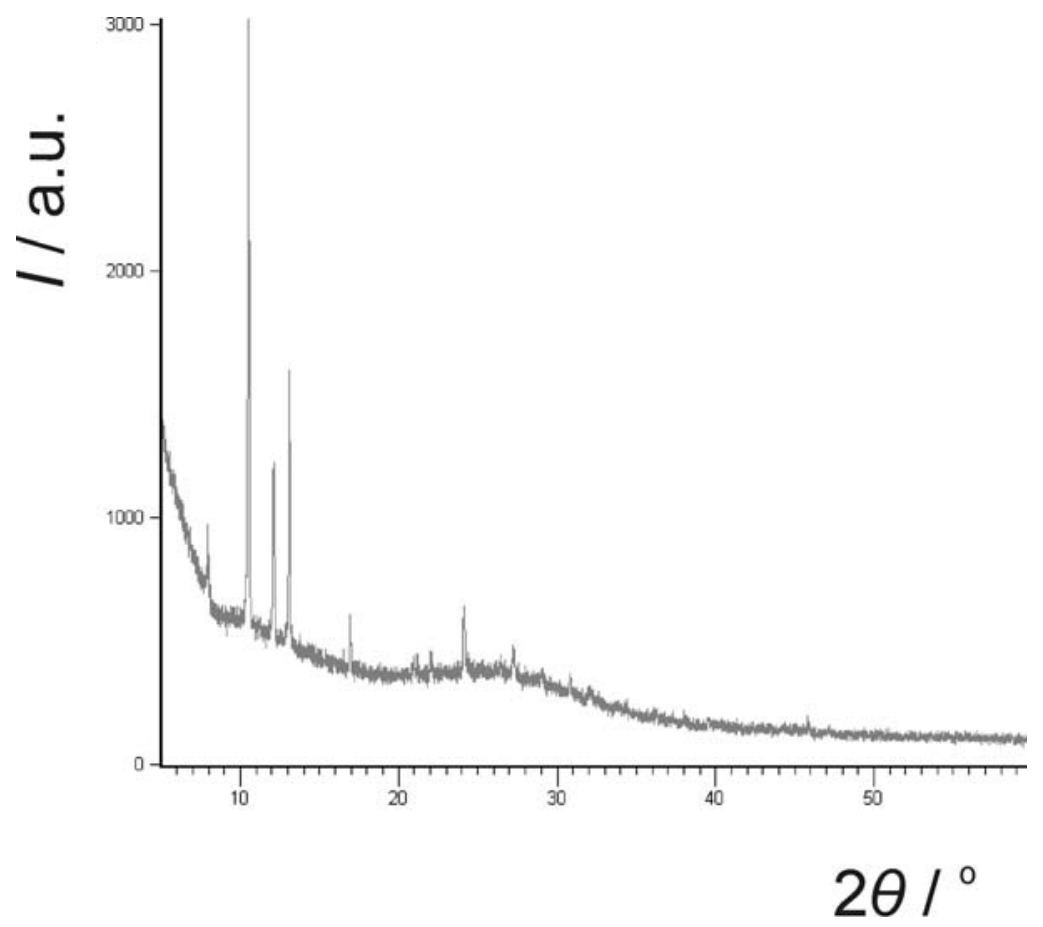

Figure S27. X-ray powder diffraction pattern of 3 after 7 days standing at $98 \%$ relative humidity.

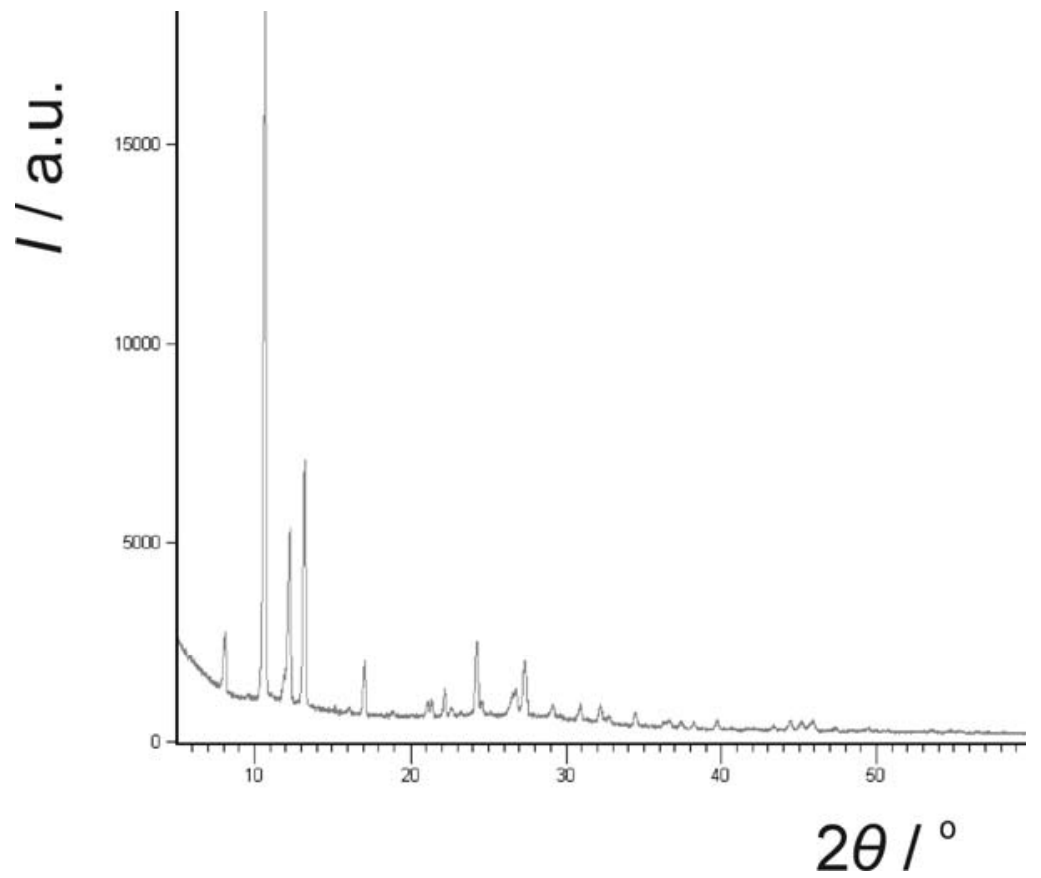

Figure S28. X-ray powder diffraction pattern of caffeine hydrate prepared by grinding anhydrous caffeine with water. 


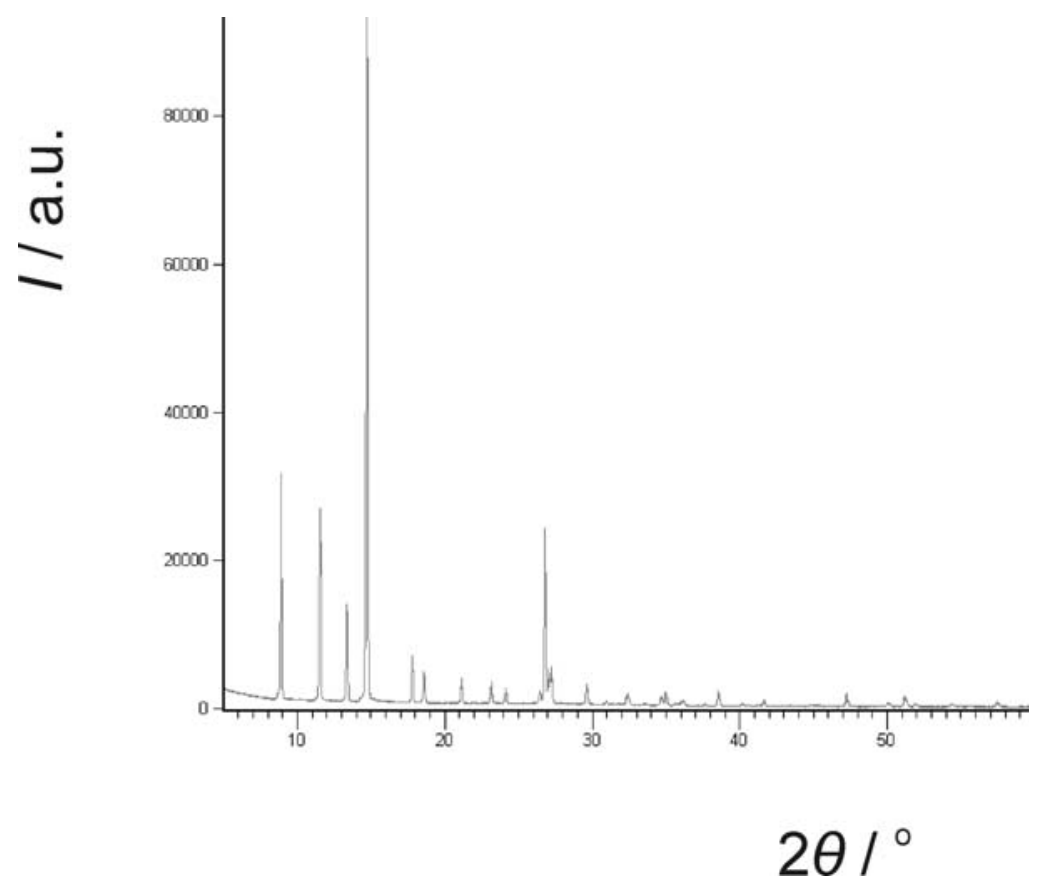

Figure S29. X-ray powder diffraction pattern of theophylline hydrate prepared by grinding anhydrous theophylline with water.

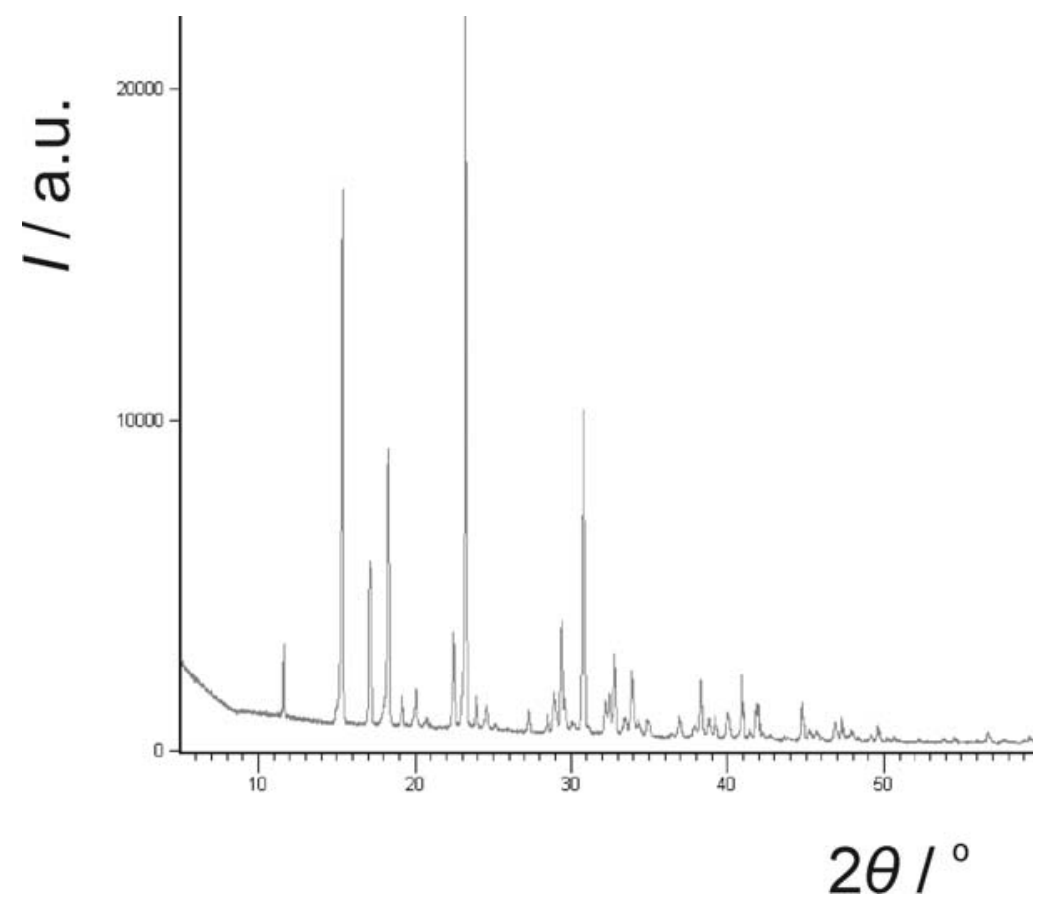

Figure S30. X-ray powder diffraction pattern of citric acid monohydrate prepared by grinding anhydrous citric acid with water. 


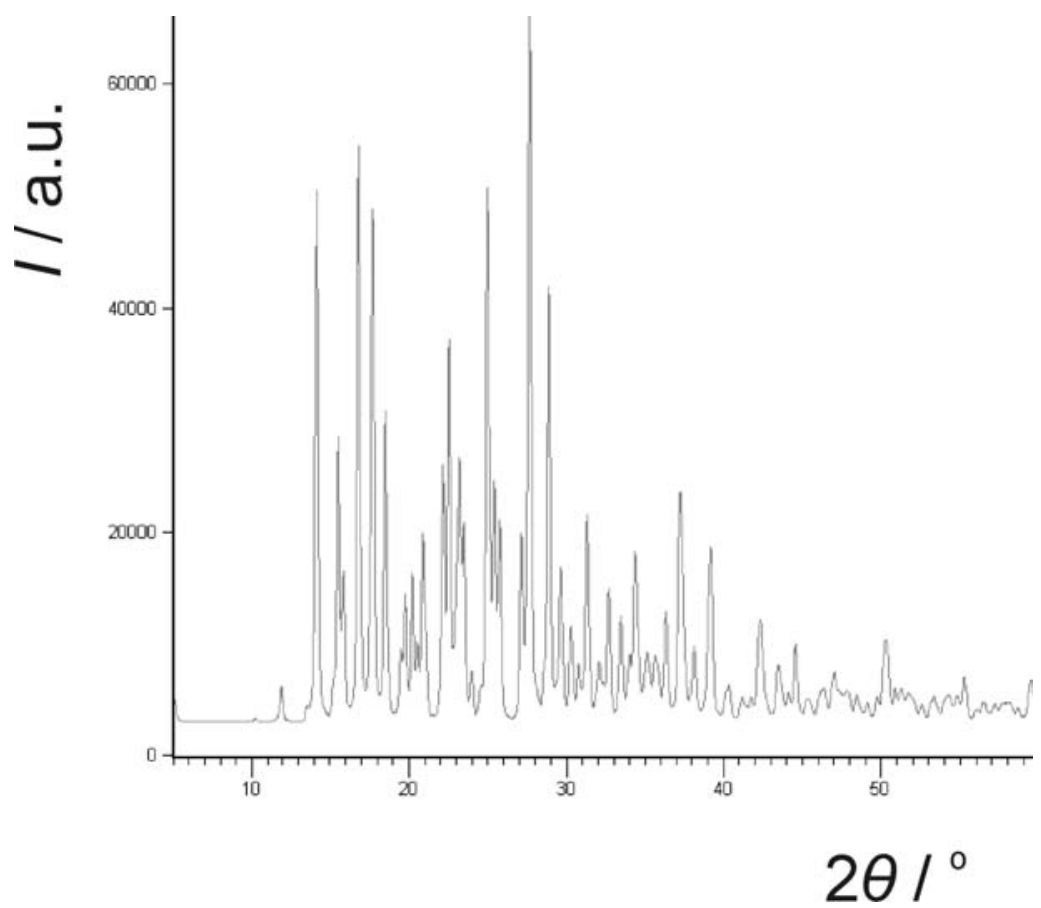

Figure S31. Simulate X-ray powder diffraction pattern of 2 .

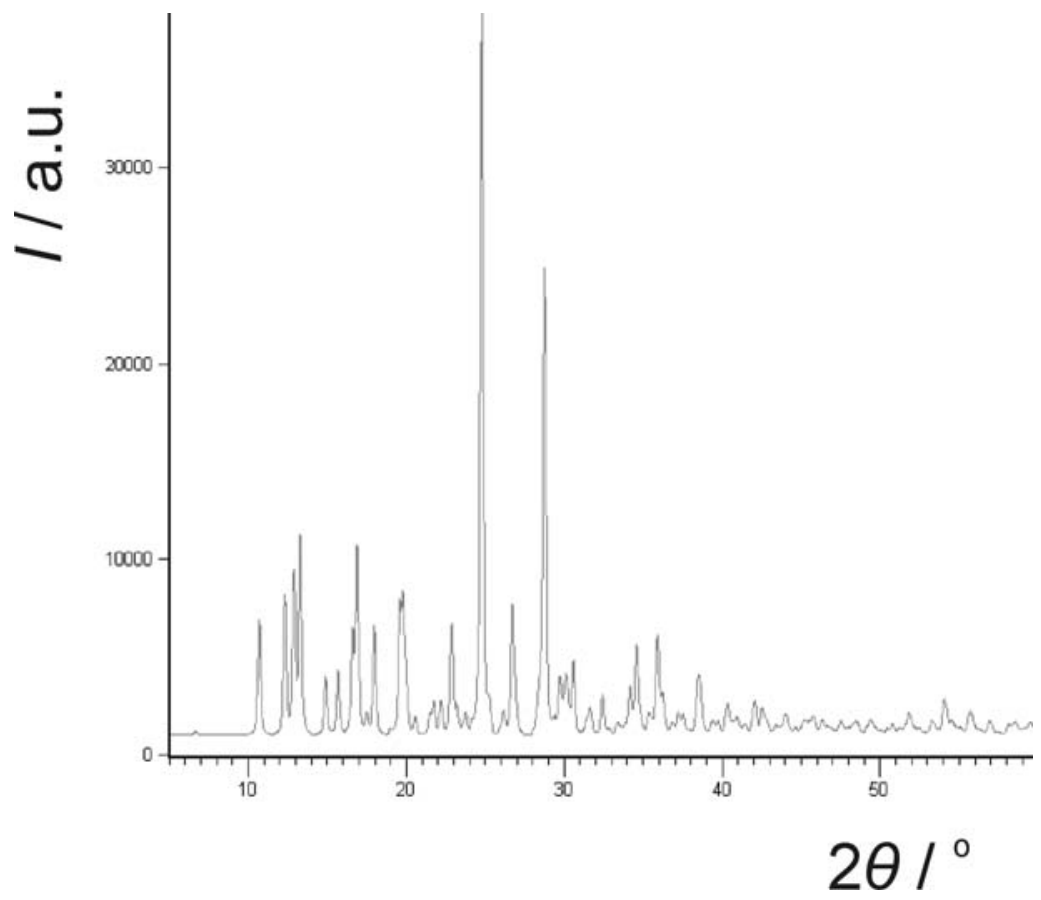

Figure S32. Simulated X-ray powder diffraction pattern of 3. 